\title{
TNF- $\alpha$ enhances vascular cell adhesion molecule-1 expression in human bone marrow mesenchymal stem cells via the NF-kB, ERK and JNK signaling pathways
}

\author{
ZI-YUAN LU ${ }^{1,2 *}$, WAN-CHENG CHEN ${ }^{1,2^{*}}$, YONG-HUA LI ${ }^{2 *}$, LI LI $^{2}$, HANG ZHANG $^{2}$, \\ YAN PANG $^{2}$, ZHI-FANG XIAO ${ }^{2}$, HAO-WEN XIAO $^{2}$ and YANG XIAO $^{1-3}$
}

\author{
${ }^{1}$ First School of Clinical Medicine, Southern Medical University, Guangzhou, Guangdong 510515; \\ ${ }^{2}$ Department of Hematology, General Hospital of Guangzhou Military Command of Chinese PLA, Guangzhou, \\ Guangdong 510010; ${ }^{3}$ Department of Hematology, The Third Affiliated Hospital of Southern Medical University, \\ Guangzhou, Guangdong 510630, P.R. China
}

Received June 3, 2015; Accepted April 4, 2016

DOI: $10.3892 / \mathrm{mmr} .2016 .5314$

\begin{abstract}
The migration of circulating mesenchymal stem cells (MSCs) to injured tissue is an important step in tissue regeneration and requires adhesion to the microvascular endothelium. The current study investigated the underlying mechanism of MSC adhesion to endothelial cells during inflammation. In in vitro MSC culture, tumor necrosis factor- $\alpha$ $(\mathrm{TNF}-\alpha)$ increased the level of vascular cell adhesion molecule-1 (VCAM-1) expression in a dose-dependent manner. The nuclear factor- $\mathrm{\kappa B}(\mathrm{NF}-\mathrm{\kappa B})$, extracellular signal-regulated kinase (ERK) and c-Jun N-terminal kinase (JNK) signaling pathway inhibitors, pyrrolidine dithiocarbamate (PDTC), U0126 and SP600125, respectively, suppressed VCAM-1 expression induced by TNF- $\alpha$ at the mRNA and protein levels $(\mathrm{P}<0.05)$. TNF- $\alpha$ augmented the activation of NF- $\mathrm{kB}, \mathrm{ERK}$ and JNK, and promoted MSC adhesion to human umbilical vein endothelial cells; however, the inhibitors of NF- $\mathrm{KB}$, ERK and JNK did not affect this process in these cells. The results of the current study indicate that adhesion of circulating MSCs to the endothelium is regulated by TNF- $\alpha$-induced VCAM-1
\end{abstract}

Correspondence to: Professor Hao-Wen Xiao, Department of Hematology, General Hospital of Guangzhou Military Command of Chinese PLA, 111 Liuhua Road, Guangzhou, Guangdong 510010, P.R. China

E-mail: haowenxiao1974@hotmail.com

Professor Yang Xiao, Department of Hematology, The Third Affiliated Hospital of Southern Medical University, 183 Zhong Shan Da Dao Xi Road, Guangzhou, Guangdong 510630, P.R. China

E-mail: jdxiao111@163.com

*Contributed equally

Key words: mesenchymal stem cells, nuclear factor- $\kappa \mathrm{B}$, extracellular signal-regulated kinase, c-Jun $\mathrm{N}$-terminal kinase, tumor necrosis factor- $\alpha$, vascular cell adhesion molecule-1 expression, which is potentially mediated by the NF- $\mathrm{BB}, \mathrm{ERK}$ and JNK signaling pathways.

\section{Introduction}

Following the first report by Friedenstein et al (1), mesenchymal stem cells (MSCs) have become a point of investigation due to their plasticity (2), potential use for tissue engineering (3) and marked immunomodulatory properties (4), and have become a widely used therapeutic method. The ability of MSCs to migrate to injury sites is a key step in their curative effect; however, various studies have demonstrated MSCs are present at low levels in the majority of target organs in non-injury models, thus, limiting their use $(5,6)$. In order to improve MSC efficacy, the underlying mechanism of MSC homing to injury sites requires investigation.

Tumor necrosis factor- $\alpha$ (TNF- $\alpha$ ) is an important pro-inflammatory cytokine and a potent regulator of MSC migration in vivo $(7,8)$. Vascular cell adhesion molecule-1 (VCAM-1) is a vital cell surface adhesion molecule expressed by various types of cell, including MSCs (9). In a previous report, Teo et al (10) suggested that, similar to leukocytes, human bone marrow-derived MSCs preferentially adhere to, and migrate across, the TNF- $\alpha$-activated endothelium in a VCAM-1 and G protein-coupled receptor signaling-dependent manner. TNF- $\alpha$-induced MSCs exhibit increased adhesion to the cardiac microvascular endothelium (CMVE) and more efficient cardiac homing, whereas TNF- $\alpha$-induced adhesion is suppressed by pretreatment with anti-VCAM-1 monoclonal antibodies in MSCs or CMVE, but not by intercellular adhesion molecule-1 (ICAM-1) (11). Thus, VCAM-1 is important for the adhesion of MSCs and CMVE, although the mechanism by which TNF- $\alpha$ stimulates MSCs to produce VCAM-1 remains unclear. In human umbilical vein endothelial cells (HUVECs), TNF- $\alpha$ induces expression of ICAM- 1 and VCAM- 1 via the extracellular signal-regulated kinase (ERK)/nuclear factor- $\mathrm{\kappa B}$ (NF- $\mathrm{kB}$ ) signaling pathway (12). Choi et al (13) demonstrated that c-Jun N-terminal kinase (JNK) inhibition increases 
TNF- $\alpha$-induced NF- $\kappa$ B activation and ICAM-1 activation. Based on these findings, it was hypothesized that, in a wound, locally produced TNF- $\alpha$ exerts a chemotactic effect on MSCs, prompting them to migrate to the site while increasing surface VCAM-1 expression, thus facilitating MSC transmigration to the target area and adhesion to the endothelium. The current study investigated the effect of TNF- $\alpha$ on MSC surface VCAM-1 expression and adhesion to endothelial cells. In addition, the activation of $\mathrm{NF}-\kappa \mathrm{B}, \mathrm{ERK}$ and JNK was examined to improve the understanding of these signal transduction pathways.

\section{Materials and methods}

Cells and culture conditions. Human MSCs were obtained from the Department of Hematology, General Hospital of Guangzhou Military Command of Chinese PLA (Guangzhou, China). The use of human samples was approved by the institution's Human and Animal Ethics Committee. Bone marrow samples were obtained with the informed consent of patients undergoing orthopedic surgery from July, 2012 to July, 2013. MSCs were isolated and cultured from bone marrow. Briefly, cells were harvested, centrifuged at $1,000 \times \mathrm{g}$ for $5 \mathrm{~min}$ and plated at a density of $6 \times 10^{5}$ cells $/ \mathrm{cm}^{2}$ in $\alpha$-minimum essential medium (Gibco; Thermo Fisher Scientific, Inc., Waltham, MA, USA) supplemented with $10 \%$ (v/v) fetal calf serum (Hyclone; Thermo Fisher Scientific, Inc., Logan, UT, USA), 20 mol/1 L-glutamine (Gibco; Thermo Fisher Scientific, Inc.) and 100 units/ml penicillin G (Gibco; Thermo Fisher Scientific, Inc.). Cells were incubated at $37^{\circ} \mathrm{C}$ in $95 \%$ humidified air with $5 \% \mathrm{CO}_{2}$. After $24 \mathrm{~h}$, non-adherent cells were removed by replacing the culture medium and the medium was subsequently changed twice a week. Upon reaching $90 \%$ confluence, the layer of adherent cells was detached using $0.25 \%$ trypsin-EDTA (Invitrogen; Thermo Fisher Scientific, Inc.), resuspended in culture medium and seeded into flasks (Costar; Corning Incorporated, Corning, NY, USA). The MSCs were used at passage 3 in all experiments.

HUVECs were provided by Sun Yat-Sen University (Guangzhou, China) and cultured in M199 essential medium (Gibco; Thermo Fisher Scientific, Inc.).

Cell treatment. Prior to each experiment, the medium was replaced with serum-free medium and the MSCs were incubated overnight. MSCs were divided into four groups: i) Without intervention; ii) stimulant alone, $50 \mathrm{ng} / \mathrm{ml} \mathrm{TNF}-\alpha$ (ProSpec-Tany TechnoGene, Ltd., East Brunswick, NJ, USA); iii) inhibitors alone, $10 \mu \mathrm{M}$ ERK inhibitor, U0126 (Cell Signaling Technology, Inc., Danvers, MA, USA), $1 \mathrm{mM}$ NF- $\mathrm{B}$ inhibitor, pyrrolidine dithiocarbamate (PDTC; Merck Millipore, Darmstadt, Germany) or $20 \mu \mathrm{M}$ JNK inhibitor, SP600125 (Merck Millipore); and iv) inhibitor + stimulant, inhibitor stimulation (as above) followed by $50 \mathrm{ng} / \mathrm{ml} \mathrm{TNF}-\alpha$. TNF- $\alpha$ treatment was applied for $24 \mathrm{~h}$ and inhibitor treatment for $1 \mathrm{~h}$. All follow-up experiments were performed in the same groups.

Measurement of VCAM-1 in MSCs by flow cytometry. The cells were cultured in media containing TNF- $\alpha$ and inhibitors within the experimental groups described. After $24 \mathrm{~h}$, the cells were harvested, fixed with 4\% paraformaldehyde (Invitrogen; Thermo Fisher Scientific, Inc.), blocked with $0.5 \%$ bovine serum albumin (Sigma-Aldrich, St. Louis, MO, USA) and incubated with a monoclonal mouse anti-human VCAM-1 phycoerythrin-conjugated antibody (cat. no. 12-1069-42; eBioscience, Inc., San Diego, CA, USA), using $5 \mu \mathrm{l}$ antibody per $10^{5}-10^{8}$ cells at $4^{\circ} \mathrm{C}$ for $30 \mathrm{~min}$. Following two washes with phosphate-buffered saline, flow cytometry was performed and analyzed using a MACS Quant flow cytometer and MACSQuantify software (Miltenyi Biotec $\mathrm{GmbH}$, Bergisch Gladbach, Germany). Each sample was measured in three different wells and the experiment was performed twice.

Reverse transcription-polymerase chain reaction ( $R T-q P C R)$. Total RNA was extracted from cells using a standard TRIzol (Takara Bio, Inc., Otsu, Japan) RNA isolation method. RT of 1 ng RNA was performed with the Takara RT Master Mix kit (Takara Bio, Inc.). RNA and cDNA quality was assessed spectrophotometrically using a Nanodrop 2000 (Thermo Fisher Scientific, Inc.) and $\beta$-actin served as an internal control. The following primers were used: Forward, 5'-GGC GCCTATACCATCCGAAA-3' and reverse 5'-AGAGCACGA GAAGCTCAGGAGAA-3' for VCAM-1; and forward, 5'-TGG CACCCAGCACAATGAA-3' and reverse, 5'-CTAAGTCAT AGTCCGCCTAGAAGCA-3' for $\beta$-actin. RT-pPCR was performed using a SYBR Premix Ex Taq kit (Takara Bio, Inc.) according to the manufacturer's instructions. The total reaction volume was $25 \mu \mathrm{l}$, and $100 \mathrm{ng}$ cDNA was used as the template. Fluorescence was detected on a Rotor-Gene Q (Qiagen $\mathrm{GmbH}$, Hilden, Germany). Data were analyzed by the quantitative $2^{-\Delta \Delta C \mathrm{C}}$ method (14) with $\beta$-actin as the endogenous control. Experiments were performed 3 times.

Western blotting. Harvested cells were lysed by incubation with radioimmunoprecipitation assay buffer containing $1 \%$ protease and phosphatase inhibitors (Thermo Fisher Scientific, Inc.) for $15 \mathrm{~min}$ at $4^{\circ} \mathrm{C}$. Lysates were centrifuged for $15 \mathrm{~min}$ at $12,000 \times \mathrm{g}$ and $4^{\circ} \mathrm{C}$, then the supernatants were collected and frozen at $-80^{\circ} \mathrm{C}$ or used immediately. Protein concentrations were determined by bicinchoninic acid assay (Pierce Biotechnology, Inc., Rockford, IL, USA). Equal quantities of proteins (20-50 $\mu \mathrm{g})$ were separated by 7.5\% SDS-PAGE and transferred to a nitrocellulose membrane (Merck Millipore, Darmstadt, Germany). Following blocking with $3 \%$ bovine serum albumin (for the phosphorylated antibodies; Thermo Fisher Scientific, Inc.) or $0.5 \%$ skimmed milk (for other antibodies) for $1.5 \mathrm{~h}$ at room temperature, membranes were incubated at $4{ }^{\circ} \mathrm{C}$ overnight with monoclonal rabbit anti-NF- $\kappa \mathrm{B}$ (cat. no. 8242), monoclonal rabbit anti-phosphorylated (p)-NF- $\kappa \mathrm{B}$ (cat. no. 4806), anti-ERK (cat. no. 9903), monoclonal rabbit anti-p-ERK (cat. no. 4370), polyclonal rabbit anti-JNK (cat. no. 9252), polyclonal rabbit anti-p-JNK (cat. no. 9251) or monoclonal rabbit anti-GAPDH (cat. no. 3683) primary antibodies (1:1,000; Cell Signaling Technology, Inc.), and then incubated with horseradish peroxidase-conjugated goat anti-rabbit secondary antibody $(1: 10,000 ;)$ for $1 \mathrm{~h}$. Immune complexes were detected with enhanced chemiluminescence reagent (Merck Millipore) and imaged with the FluorChem Q system (ProteinSimple, San Jose, CA, USA). Equal protein loading was confirmed by measuring the GAPDH or total protein expression. The results 
were analyzed using Image J2x software (version 2.1.4.7; www.rawak.de/rs2012/). Western blot analysis was performed three times.

Cell adhesion assay. Cells were treated with control, TNF- $\alpha$ alone $(50 \mathrm{ng} / \mathrm{ml})$ or TNF- $\alpha$ with inhibitor (1 mM PDTC, $10 \mu \mathrm{M}$ U0126 or 20 mM SP600125). MSC adherence to HUVECs was measured using fluorescent carbocyanine CM-Dil (Invitrogen; Thermo Fisher Scientific, Inc.) to label the cell membranes. Minor modifications were made to the manufacturer's protocol. Briefly, prior to transplantation, MSCs were labeled with $2 \mu \mathrm{g} / \mathrm{ml} \mathrm{CM}$-Dil for $\sim 30 \mathrm{~min}$ at $37^{\circ} \mathrm{C}$, then washed three times with phosphate-buffered saline (Thermo Fisher Scientific, Inc.) and transferred to a 6-well plate containing HUVECs for $12 \mathrm{~h}$. Non-adherent cells were removed by washing with medium. The number of adherent cells were counted in 5 fields of each sample $(n=4)$ at $x 4$ magnification (BX51M; Olympus Corporation, Tokyo, Japan).

Statistical analysis. The data represent a minimum of three independent experiments and are expressed as means \pm standard deviation. Data analysis was performed with SPSS software version 13.0 (SPSS, Inc., Chicago, IL, USA). One-way analysis of variance followed by Tukey's test were performed and $\mathrm{P}<0.05$ was considered to indicate a statistically significant difference.

\section{Results}

TNF- $\alpha$ upregulates VCAM-1 expression in MSCs in a dose-dependent manner. The effect of TNF- $\alpha$ on VCAM-1 expression in MSCs was investigated by flow cytometry. The analysis demonstrated that, compared with the control, the VCAM-1 expression level was increased by TNF- $\alpha$ in a dose-dependent manner $(\mathrm{P}=0.000)$. VCAM-1 expression levels peaked at $50 \mathrm{ng} / \mathrm{ml} \mathrm{TNF-} \alpha$ treatment. Thus, $50 \mathrm{ng} / \mathrm{ml}$ TNF- $\alpha$ was selected as the stimulating concentration for the subsequent experiments (Fig. 1).

PDTC, U0126 and SP600125 inhibit induction of VCAM-1 by TNF- $\alpha$. To determine whether PDTC, U0126, or SP600125 influenced the VCAM-1 expression level, flow cytometry and RT-qPCR were used to measure VCAM-1 protein and mRNA expression levels, respectively. MSCs were pre-incubated with the inhibitors and subsequently stimulated with TNF- $\alpha$. Under these conditions, surface VCAM-1 expression was significantly reduced in MSCs treated with the inhibitors when compared with those that received TNF- $\alpha$ treatment alone $(\mathrm{P}=0.000)$. Notably, MSCs treated with inhibitors alone demonstrated no difference in VCAM-1 expression level when compared with the control group (Fig. 2A-J).

Similarly, these trends were reflected in the VCAM-1 mRNA level (Fig. 2K). The groups treated with TNF- $\alpha$ and inhibitors demonstrated a significant decrease in the VCAM-1 mRNA expression level when compared with the TNF- $\alpha$ group (PDTC, P=0.005; U0126, P=0.001; SP6000125, P=0.004). By contrast, the inhibitors alone exhibited no apparent suppressive effect. Thus, the changes observed by flow cytometry were more obvious than those demonstrated by VCAM-1 mRNA expression.

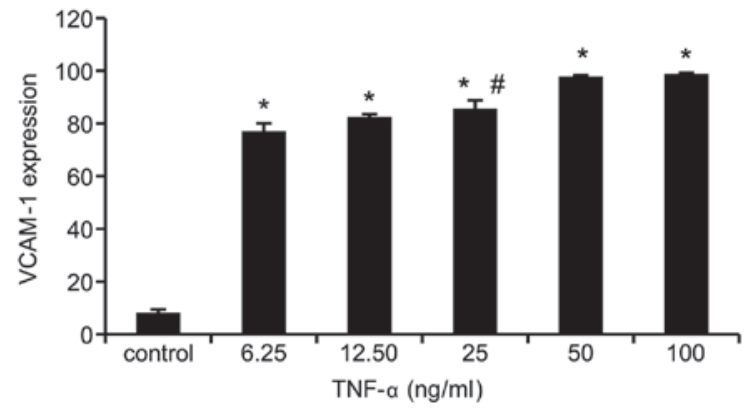

Figure 1. Effect of TNF- $\alpha$ on VCAM-1 expression in MSCs. MSCs were stimulated with TNF- $\alpha(0,6.25,12.50,25,50$ and $100 \mathrm{ng} / \mathrm{ml})$ for $24 \mathrm{~h}$ and analyzed by flow cytometry. Data were obtained from three separate experiments and are presented as means \pm standard deviation. ${ }^{*} \mathrm{P}<0.05$ vs. control, ${ }^{\#} \mathrm{P}<0.05$ vs. $50 \mathrm{ng} / \mathrm{ml}$. VCAM-1, vascular cell adhesion molecule 1 ; TNF- $\alpha$, tumor necrosis factor- $\alpha$; MSCs, mesenchymal stem cells.

Effects of TNF- $\alpha$ on the phosphorylation of $N F-\kappa B, E R K$ and $J N K$. To examine the TNF- $\alpha$ regulated activation of the $\mathrm{NF}-\kappa \mathrm{B}, \mathrm{ERK}$ or JNK signaling pathways, western blot analysis was used to detect protein phosphorylation in each pathway. MSCs were divided into three groups: Control, TNF- $\alpha$, and MSCs stimulated with inhibitor + TNF- $\alpha$. It was demonstrated that TNF- $\alpha$ significantly increased the activation of all three signaling pathways (NF- $\kappa \mathrm{B}$, ERK and JNK) compared with the control $(\mathrm{P}=0.001, \mathrm{P}=0.001$ and $\mathrm{P}=0.032$, respectively); however, the increased activation was reduced by pretreatment with inhibitors. Furthermore, treatment with inhibitor $+\mathrm{TNF}-\alpha$ significantly reduced the phosphorylation of NF- $\kappa \mathrm{B}$ and ERK when compared with the TNF- $\alpha$ alone group ( $\mathrm{P}=0.046$ and $\mathrm{P}=0.036$, respectively; Fig. 3 ).

Effects of TNF- $\alpha$, PDTC, U0126 and SP600125 on MSC adhesion to HUVECs. Finally, the effects of TNF- $\alpha$ and the inhibitors on MSC adhesion were investigated. The number of MSCs was significantly increased in the TNF- $\alpha$-induced group compared with the control $(\mathrm{P}=0.000)$. However, the combined treatment of signaling pathway inhibitors and TNF- $\alpha$ did not demonstrate a marked effect on MSC adhesion when compared with control (Fig. 4).

\section{Discussion}

MSCs have been applied in the treatment of a variety of diseases, however, the precise mechanisms underlying MSC homing to injured tissues are not fully understood (15-19). The current study demonstrated various important findings regarding the effect of TNF- $\alpha$ on VCAM-1 expression in human bone marrow-derived MSCs. The present study demonstrated that TNF- $\alpha$ treatment increased the level of VCAM-1 expression in MSCs in a dose-dependent manner. Additionally, the signaling pathway inhibitors, PDTC, U0126 and SP600125 suppressed VCAM-1 expression induced by TNF- $\alpha$. Furthermore, TNF- $\alpha$ augmented the activities of NF- $\mathrm{B}, \mathrm{ERK}$ and JNK, and promoted MSC adhesion to HUVECs, while the signaling pathway inhibitors exhibited no observable effect on adhesion.

Following intravenous injection, MSCs circulate in the blood stream and adhesion to endothelial cells at sites of injury is the first step in homing of MSCs to target 

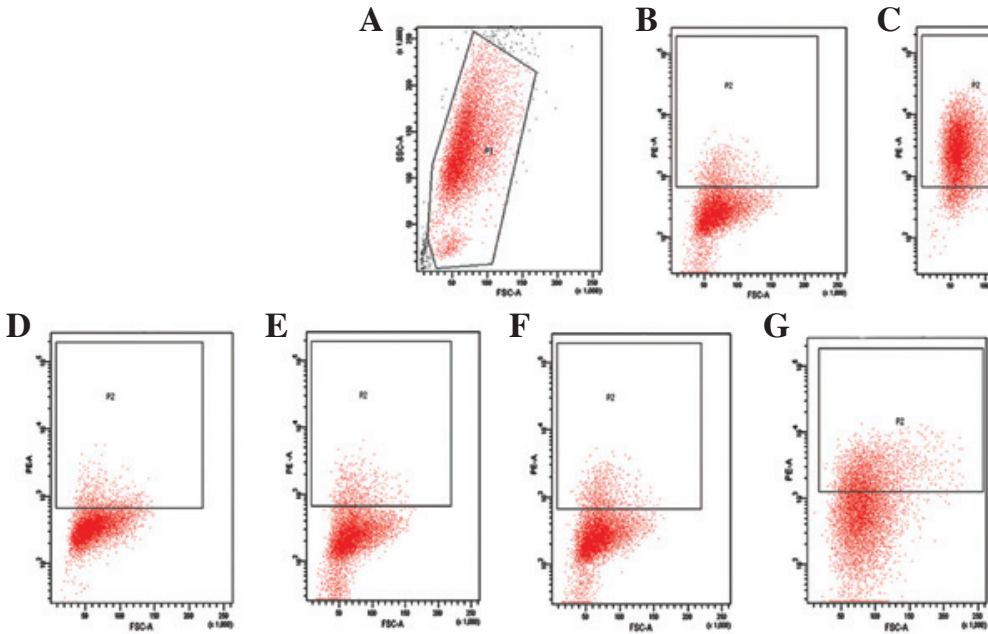

H
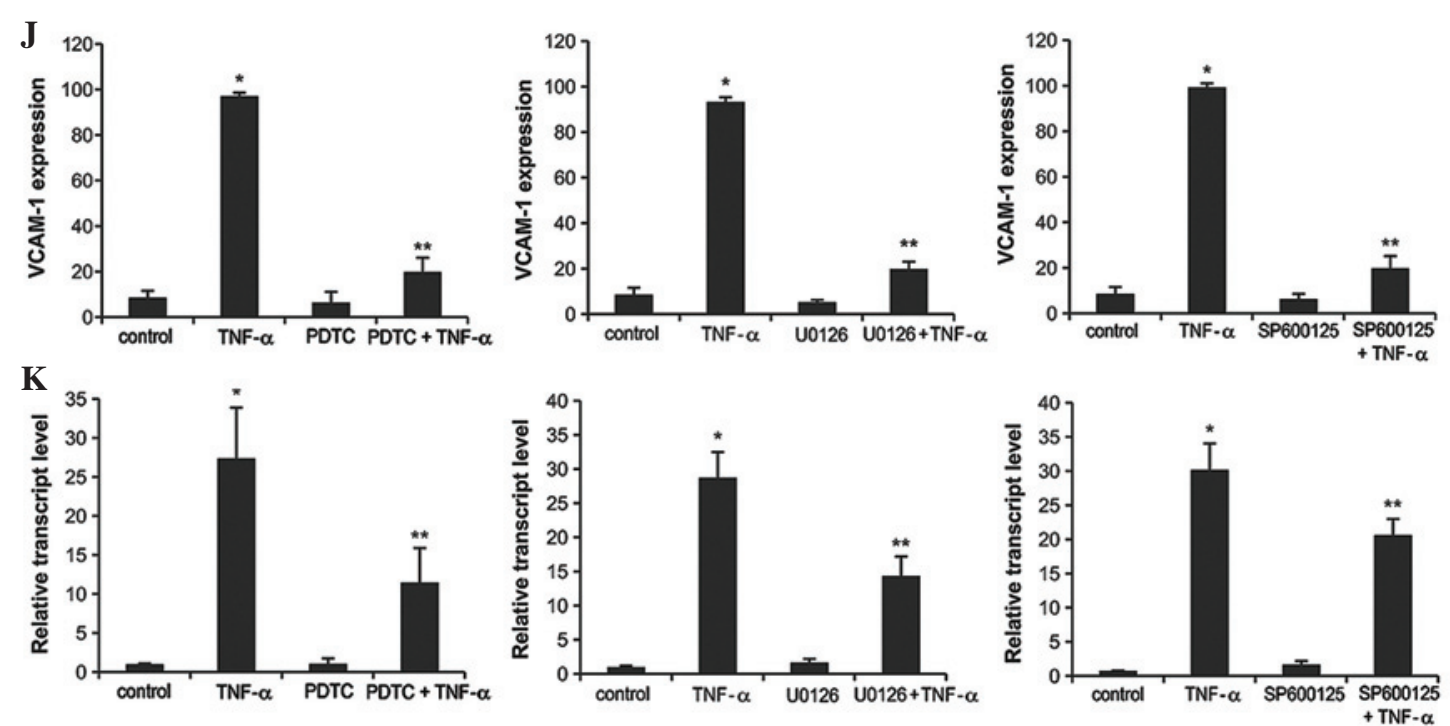

Figure 2. PDTC, U0126, and SP600125 blocked TNF- $\alpha$-induced VCAM-1 expression in MSCs. (A) The appropriate active MSCs were analyzed by flow cytometry. (B) VCAM-1 expression of MSCs in control cells measured by flow cytometry. The effects of (C) TNF- $\alpha$ or (D) nuclear factor- $\kappa \mathrm{B}$ inhibitor, PDTC, (E) ERK inhibitor, U0126, (F) JNK inhibitor, SP600125 on VCAM-1 expression levels were measured by flow cytometry. Additionally, the combined effect of TNF- $\alpha$ and (G) PDTC, (H) U0126 and (I) SP600125 on VCAM-1 expression were determined by flow cytometry and (J) quantified. (K) Reverse transcription-quantitative polymerase chain reaction was performed to measure the VCAM-1 mRNA expression levels from the same treatment groups. Data were obtained from three independent experiments and are presented as means \pm standard deviation. ${ }^{*} \mathrm{P}<0.05$ vs. control, ${ }^{* *} \mathrm{P}<0.05$ vs. TNF- $\alpha$ group. PDTC, pyrrolidine dithiocarbamate; TNF- $\alpha$, tumor necrosis factor- $\alpha$; VCAM-1, vascular cell adhesion molecule 1; ERK, extracellular signal-regulated kinase; JNK, c-Jun N-terminal kinase.

organs. Inflammatory cytokines, including $\mathrm{TNF}-\alpha$ and interleukin-1 $\beta$, enhance the adhesion of MSCs to CMVE in vitro and in vivo (11). TNF- $\alpha$ activates MSCs by binding to surface receptors. There are two major receptors, TNF receptor I and II, expressed in human MSCs (20). TNF- $\alpha$ interacts with its receptors and activates downstream intracellular signaling pathways. In rat MSCs, VCAM-1 expression, which was induced by platelet-derived growth factor BB, required activation of phosphatidylinositol-4,5-bisphosphate 3-kinase (PI3K), p38 mitogen-activated protein kinase and $\mathrm{NF}-\kappa \mathrm{B}$ (21). Furthermore, PI3K is involved in the signal transduction of vascular endothelial growth factor-induced migration and VCAM-1 expression of bone marrow-derived MSCs (22). Uchibori et al (23) demonstrated that NF- $\kappa \mathrm{B}$ signaling regulates MSC accumulation at tumor sites. The present study demonstrated that human VCAM-1 expression in MSCs stimulated by TNF- $\alpha$ was dependent on $N F-\kappa B$,
ERK and JNK signaling. However, the signaling activity of cells pretreated with SP600125 and then stimulated with TNF- $\alpha$ demonstrated no observable change when compared with the control group. This indicates that the JNK signaling pathway is not required for TNF- $\alpha$-induced VCAM-1 expression in MSCs.

Notably, VCAM-1 and its major ligand, integrin $\alpha 4 \beta 1$, are expressed in MSCs and the microvascular endothelium. However, it was previously demonstrated that integrin $\alpha 4 \beta 1$ expression does not change significantly following TNF- $\alpha$ stimulation (23). Fu et al (7) demonstrated that expression of ICAM-1 was increased by $50 \mu \mathrm{g} / 1 \mathrm{TNF}-\alpha$ in rat MSCs, whereas VCAM-1 expression did not change. Another study demonstrated that TNF- $\alpha$ induces VCAM-1 expression in rat MSCs in a concentration-dependent manner (24). The current study demonstrated that TNF- $\alpha$ increases VCAM-1 expression in a dose-dependent manner in human MSCs. 
A
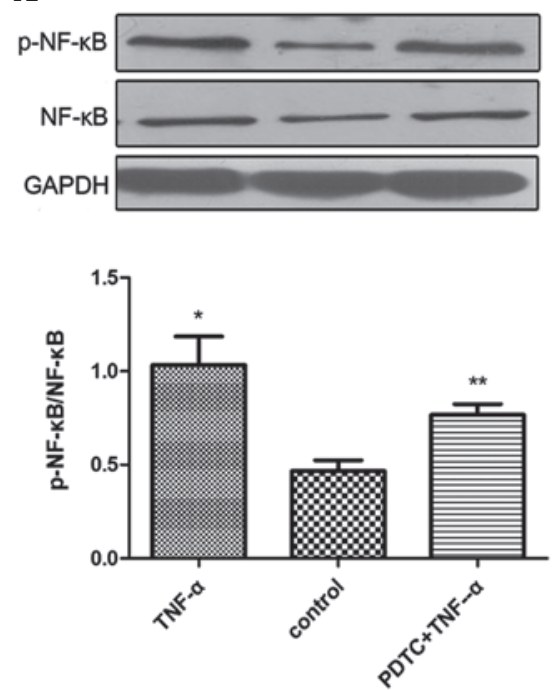

B
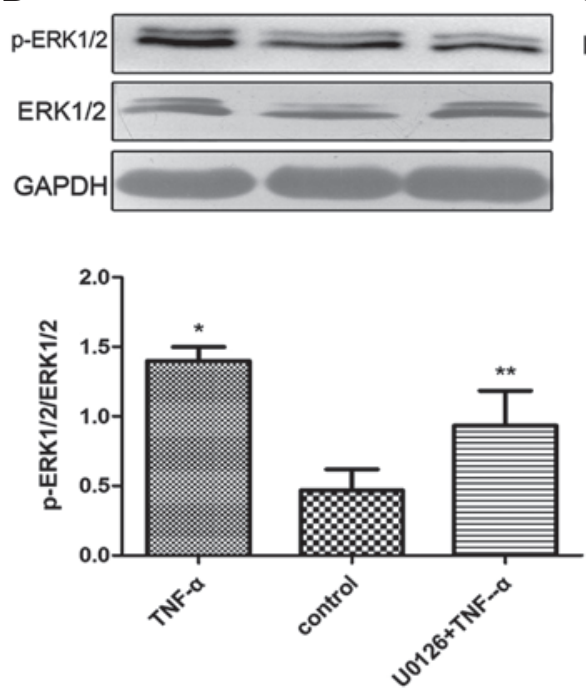

C
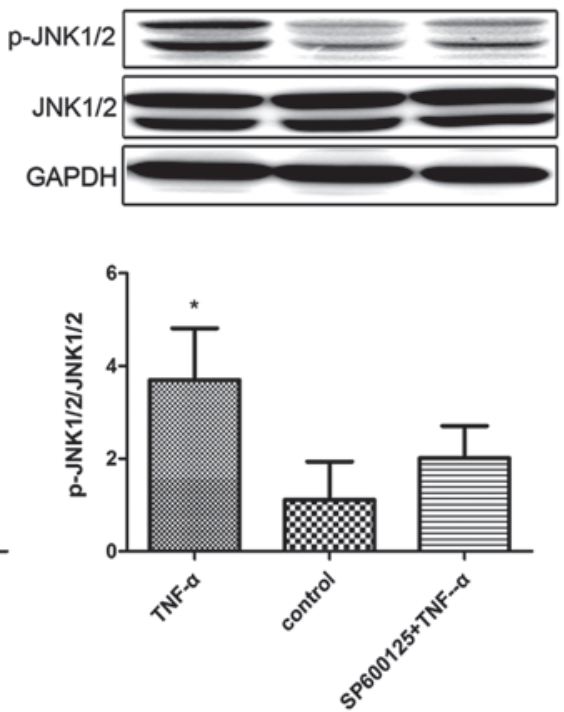

Figure 3. Activity of NF- $\mathrm{BB}$, ERK, or JNK signaling in MSCs treated with TNF- $\alpha+$ inhibitors and TNF- $\alpha$ alone. (A) Effect of TNF- $\alpha$ and NF- $\mathrm{BB}$ inhibitor, PDTC on NF-KB signaling. (B) Effect of TNF- $\alpha$ and ERK inhibitor, U0126 on ERK signaling. (C) Effect of TNF- $\alpha$ and JNK inhibitor, SP600125 on the JNK signaling pathway. Data were obtained from three independent experiments and are presented as means \pm standard deviation. ${ }^{*} \mathrm{P}<0.05$ vs. control, ${ }^{* * *} \mathrm{P}<0.05$

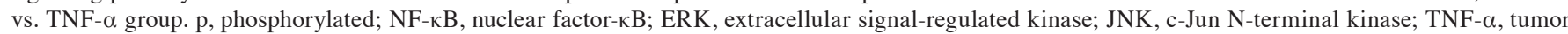
necrosis factor- $\alpha$; MSCs, mesenchymal stem cells.

A

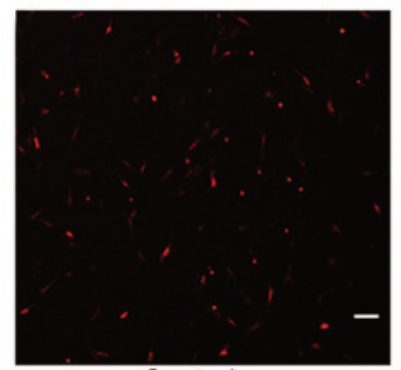

Control

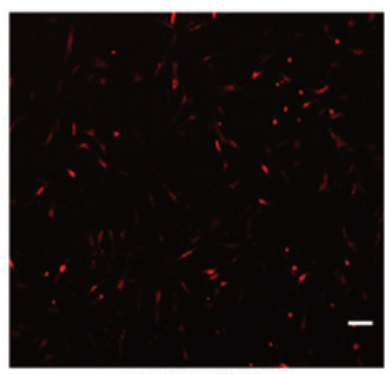

U0126+TNF-a

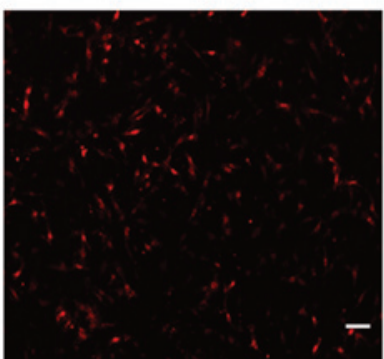

TNF- $\alpha$

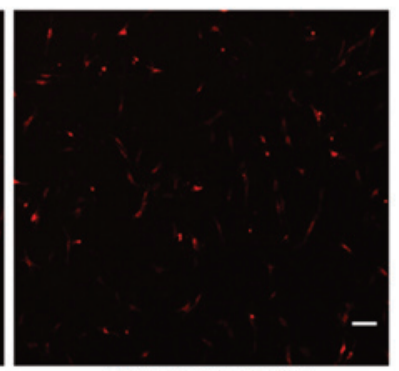

Sp600125+TNF-a

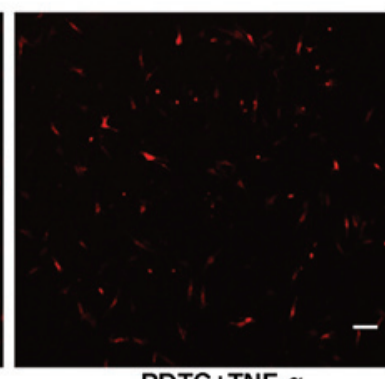

PDTC+TNF- $\alpha$

B

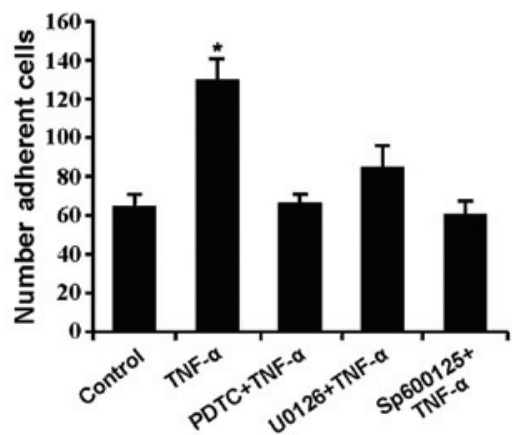

Figure 4. Effects of TNF- $\alpha$, PDTC, U0126 and SP600125 on MSC adhesion to human umbilical vein endothelial cells. (A) MSCs were divided into four groups: Untreated control cells; $50 \mathrm{ng} / \mathrm{ml} \mathrm{TNF}-\alpha$ treatment; $50 \mathrm{ng} / \mathrm{ml} \mathrm{TNF}-\alpha$ treatment $+1 \mathrm{mM} \mathrm{PDTC,} 50 \mathrm{ng} / \mathrm{ml} \mathrm{TNF}-\alpha$ treatment $+10 \mu \mathrm{M}$ U0126 or $50 \mathrm{ng} / \mathrm{ml}$ TNF- $\alpha$ treatment +20 mM SP600125. Representative photomicrographs of MSCs are presented (scale bar, $100 \mu \mathrm{m})$. Experiment was performed 4 times. (B) Quantitative analyses of the number of adherent cells. Data are presented as the mean \pm standard deviation. "P<0.05 vs. control. TNF- $\alpha$, tumor necrosis factor- $\alpha$; PDTC, pyrrolidine dithiocarbamate; MSCs, mesenchymal stem cells.

Segers et al (11) demonstrated that TNF- $\alpha$-stimulated adhesion of CMVE or MSCs is blocked by pretreatment with anti-VCAM-1 monoclonal antibodies, but not by anti-ICAM-1 antibodies. Thus, MSC adherence to the vascular endothelium is predominantly mediated by VCAM-1 expression. The results of the current study demonstrate that TNF- $\alpha$ treatment increased the adhesion of MSCs when compared with the controls.

In conclusion, the present study demonstrated that TNF- $\alpha$ upregulates VCAM-1 expression in human bone marrow-derived MSCs and facilitates adherence to the vascular endothelium at sites of injury. Furthermore, TNF- $\alpha$-induced 
adhesion is partially mediated by the NF- $\kappa \mathrm{B}$, ERK and JNK signaling pathways. In the clinical setting, MSCs are used as therapeutic means to treat patients with Graft versus host disease and aplastic anemia. They improve the symptoms and the patient survival rates, however the curative effect varies. Few MSCs settle in bone marrow, thus, it is important to improve the homing capacity of MSCs. MSCs adherence to HUVECs is an important step for homing. The findings of the current study provide insight into the molecular mechanism of this process. In future studies, TNF- $\alpha$ and other cytokines may be used stimulate MSCs in vitro to upregulate their homing capacities. Subsequently, administration of the MSCs to patients may improve their curative effect.

\section{Acknowledgements}

The current study was supported by grants from the National Natural Science Foundation of China (grant no. 30900645), Guangzhou Pearl River Scientific and Technological New Star Capitals (grant no. 2012J2200008), and Medical Science and Technology Research of the 12th 'Five-Year' Planning's Key Project of Chinese Army (grant no. BWS11J071).

\section{References}

1. Friedenstein AJ, Chailakhyan RK, Latsinik NV, Panasyuk AF and Keiliss-Borok IV: Stromal cells responsible for transferring the microenvironment of the hemopoietic tissues. Cloning in vitro and retransplantation in vivo. Transplantation 17: 331-340, 1974.

2. Pittenger MF, Mackay AM, Beck SC, Jaiswal RK, Douglas R, Mosca JD, Moorman MA, Simonetti DW, Craig S and Marshak DR: Multilineage potential of adult human mesenchymal stem cells. Science 284: 143-147, 1999.

3. Caplan AI: Adult mesenchymal stem cells for tissue engineering versus regenerative medicine. J Cell Physiol 213: 341-347, 2007.

4. Nauta AJ and Fibbe WE: Immunomodulatory properties of mesenchymal stromal cells. Blood 110: 3499-3506, 2007.

5. Gao J, Dennis JE, Muzic RF, Lundberg M and Caplan AI: The dynamic in vivo distribution of bone marrow-derived mesenchymal stem cells after infusion. Cells Tissues Organs 169: $12-20,2001$.

6. Devine SM, Cobbs C, Jennings M, Bartholomew A and Hoffman R: Mesenchymal stem cells distribute to a wide range of tissues following systemic infusion into nonhuman primates. Blood 101: 2999-3001, 2003.

7. Fu X, Han B, Cai S, Lei Y, Sun T and Sheng Z: Migration of bone marrow-derived mesenchymal stem cells induced by tumor necrosis factor-alpha and its possible role in wound healing. Wound Repair Regen 17: 185-191, 2009.

8. Zhang A, Wang Y, Ye Z, Xie H, Zhou L and Zheng S: Mechanism of TNF- $\alpha$-induced migration and hepatocyte growth factor production in human mesenchymal stem cells. J Cell Biochem 111: 469-475, 2010.

9. Bühring HJ, Treml S, Cerabona F, de Zwart P, Kanz L and Sobiesiak M: Phenotypic characterization of distinct human bone marrow-derived MSC subsets. Ann N Y Acad Sci 1176 124-134, 2009.
10. Teo GS, Ankrum JA, Martinelli R, Boetto SE, Simms K, Sciuto TE, Dvorak AM, Karp JM and Carman CV: Mesenchymal stem cells transmigrate between and directly through tumor necrosis factor- $\alpha$-activated endothelial cells via both leukocyte-like and novel mechanisms. Stem Cells 30: 2472-2486, 2012.

11. Segers VF, Van Riet I, Andries LJ, Lemmens K, Demolder MJ, De Becker AJ, Kockx MM and De Keulenaer GW: Mesenchymal stem cell adhesion to cardiac microvascular endothelium: Activators and mechanisms. Am J Physiol Heart Circ Physiol 290: H1370-H1377, 2006.

12. Zhong X, Li X, Liu F, Tan H and Shang D: Omentin inhibits TNF- $\alpha$-induced expression of adhesion molecules in endothelial cells via ERK/NF-kB pathway. Biochem Biophys Res Commun 425: 401-406, 2012.

13. Choi H, Nguyen HN and Lamb FS: Inhibition of endocytosis exacerbates TNF- $\alpha$-induced endothelial dysfunction via enhanced JNK and p38 activation. Am J Physiol Heart Circ Physiol 306: H1154-H1163, 2014

14. Livak KJ and Schmittgen TD: Analysis of relative gene expression data using real-time quantitative PCR and the 2(-Delta Delta C(T)) Method. Methods 25: 402-408, 2001.

15. Xiao Y, Jiang ZJ, Pang Y, Li L, Gao Y, Xiao HW, Li YH, Zhang $\mathrm{H}$ and Liu Q: Efficacy and safety of mesenchymal stem cell treatment from related donors for patients with refractory aplastic anemia. Cytotherapy 15: 760-766, 2013.

16. Rodrigo SF, van Ramshorst J, Hoogslag GE, Boden H, Velders MA, Cannegieter SC, Roelofs H, Al Younis I, Dibbets-Schneider P, Fibbe WE, et al: Intramyocardial injection of autologous bone marrow-derived ex vivo expanded mesenchymal stem cells in acute myocardial infarction patients is feasible and safe up to 5 years of follow-up. J Cardiovasc Transl Res 6: 816-825, 2013.

17. Huleihel L, Levine M and Rojas M: The potential of cell-based therapy in lung diseases. Expert Opin Biol Ther 13: 1429-1440, 2013.

18. Undale AH, Westendorf JJ, Yaszemski MJ and Khosla S: Mesenchymal stem cells for bone repair and metabolic bone diseases. Mayo Clin Proc 84: 893-902, 2009.

19. Weng JY, Du X, Geng SX, Peng YW, Wang Z, Lu ZS, Wu SJ, Luo CW, Guo R, Ling W, et al: Mesenchymal stem cell as salvage treatment for refractory chronic GVHD. Bone Marrow Transplant 45: 1732-1740, 2010.

20. Croitoru-Lamoury J, Lamoury FM, Zaunders JJ, Veas LA and Brew BJ: Human mesenchymal stem cells constitutively express chemokines and chemokine receptors that can be upregulated by cytokines, IFN-beta and Copaxone. J Interferon Cytokine Res 27: 53-64, 2007.

21. Hu Y, Cheng P, Ma JC, Xue YX and Liu YH: Platelet-derived growth factor $\mathrm{BB}$ mediates the glioma-induced migration of bone marrow-derived mesenchymal stem cells by promoting the expression of vascular cell adhesion molecule-1 through the PI3K, P38 MAPK and NF-kB pathways. Oncol Rep 30: 2755-2764, 2013.

22. Gao Z, Cheng P, Xue Y and Liu Y: Vascular endothelial growth factor participates in modulating the C6 glioma-induced migration of rat bone marrow-derived mesenchymal stem cells and upregulates their vascular cell adhesion molecule-1 expression. Exp Ther Med 4: 993-998, 2012.

23. Uchibori R, Tsukahara T, Mizuguchi H, Saga Y, Urabe M, Mizukami H, Kume A and Ozawa K: NF-kB activity regulates mesenchymal stem cell accumulation at tumor sites. Cancer Res 73: 364-372, 2013.

24. Xiao Q, Wang SK, Tian H, Xin L, Zou ZG, Hu YL, Chang CM, Wang XY, Yin QS, Zhang XH and Wang LY: TNF- $\alpha$ increases bone marrow mesenchymal stem cell migration to ischemic tissues. Cell Biochem Biophys 62: 409-414, 2012. 